\title{
Area-Selective Atomic Layer Deposition Using an Inductively Coupled Plasma Polymerized Fluorocarbon Layer: A Case Study for Metal Oxides
}

\author{
Ali Haider, ${ }^{*}, \ddagger$ Petro Deminskyi, ${ }^{\ddagger}$ Talha M. Khan, ${ }^{\dagger \dagger}$ Hamit Eren, ${ }^{\dagger, \ddagger}$ and Necmi Biyikli*, ${ }^{\dagger}$ \\ ${ }^{\dagger}$ Institute of Materials Science and Nanotechnology, Bilkent University, Ankara 06800, Turkey \\ ${ }^{\ddagger}$ UNAM - National Nanotechnology Research Center, Bilkent University, Ankara 06800, Turkey \\ ${ }^{\S}$ Electrical and Computer Engineering Department, Utah State University, Logan, Utah 84322, United States
}

Supporting Information

\begin{abstract}
Area-selective atomic layer deposition (ASALD) has attracted immense attention in recent years for self-aligned accurate pattern placement with subnanometer thickness control. Here, we demonstrate a methodology to achieve AS-ALD by using inductively couple plasma (ICP) grown fluorocarbon polymer film as hydrophobic blocking layer for selective deposition. Our approach has been tested for metal-oxide materials including $\mathrm{ZnO}, \mathrm{Al}_{2} \mathrm{O}_{3}$, and $\mathrm{HfO}_{2}$. Contact angle, X-ray photoelectron spectroscopy (XPS), spectroscopic ellipsometer, and scanning electron microscopy (SEM) measurements were performed to investigate the blocking ability of plasma polymerized fluorocarbon layers against ALD-grown metal-oxide films. A considerable growth inhibition for $\mathrm{ZnO}$ has been observed on fluorocarbon coated $\mathrm{Si}(100)$ surfaces, while the same polymerized surface caused a relatively slow nucleation for $\mathrm{HfO}_{2}$ films. No growth selectivity was obtained for $\mathrm{Al}_{2} \mathrm{O}_{3}$ films, displaying almost the same nucleation behavior on $\mathrm{Si}$ and fluorocarbon surfaces. Thin film patterning has been demonstrated using this strategy by growing $\mathrm{ZnO}$ on lithographically patterned fluorocarbon/Si samples. High resolution SEM images and XPS line scan confirmed the successful patterning of ZnO up to a film thickness of $\sim 15 \mathrm{~nm}$.
\end{abstract}

\section{INTRODUCTION}

Micro and nanoscale film patterning is an essential part of modern microelectronics industry, being the essential ingredients of Si-based CMOS transistor technology. As device scaling proceeds toward sub-10 $\mathrm{nm}$ era where process tolerances become atomic-scale, the adoption of alternative nanoscale process integration schemes become critical for both Moore's law (extension of device down-scaling) and beyond Moore (novel device concepts). Nanoscale process integration demands novel nanopatterning techniques in compliance with the requirements of feature generation devices. Conventionally, top-down subtractive (etch) or additive (deposition/lift-off) processes in conjunction with various lithography techniques is employed to achieve film patterning, which becomes increasingly challenging due to the ever-shrinking alignment requirements. $^{1-3}$ To reduce the complexity burden of lithographic alignment in future technology nodes, self-aligned processes such as selective deposition and selective etching might provide vital solutions.

In recent years, area-selective atomic layer deposition (ASALD) has attracted significant attention as a powerful alternative path for the realization of nanoscale film patterning. ${ }^{4-10}$ ALD is a low-temperature vapor phase growth technique, in which ultrathin film growth is carried out by exposing the substrate to alternate pulsing of two precursors featuring surface chemisorption and ligand exchange reactions. After a sufficient precursor dosage, all reactive sites on the substrate are occupied and saturated with the precursor molecules, known as "self-limiting" growth mechanism referring to a growth regime independent of the precursor flux/dose. Major advantages of ALD include large area uniformity, excellent three-dimensional (3D) conformality, and unparalleled subangstrom level thickness control. ${ }^{11-13}$

Since ALD relies heavily on surface chemistry, it is possible to chemically modify the surface to achieve AS-ALD. Such ALD-enabled nanopatterning approaches have been classified into two categories; (i) area-activated AS-ALD ${ }^{4,14-22}$ and (ii) area-deactivated AS-ALD. ${ }^{12,23-35}$ So far, most of the AS-ALD studies have been performed with area deactivation, where part of the substrate is blocked/deactivated by certain coatings allowing film to grow only on the uncovered areas. Surface deactivation has been typically achieved by selectively attaching self-assembled monolayers (SAMs) on the substrate surface. SAMs are monolayer films which are comprised of relatively long organic chains with reactive groups at both ends. The headgroup, alkane chain, and a tail group are the main

Received: September 17, 2016

Revised: October 23, 2016

Published: November 1, 2016 
constituents of SAMs. Head group facilitates the adsorption of the molecule on to the substrate surface while tail group terminates the surface and exposes itself directly for ALD reaction. An ordered SAM is formed due to van der Waals interactions between the alkane chains. The tail group determines the property of the surface termination either as hydrophilic or hydrophobic which in turn either enhances or blocks the nucleation and growth of ALD grown films. ${ }^{7,36,37}$ AS-ALD of $\mathrm{TiO}_{2}{ }^{26,30,38,39} \mathrm{ZnO},{ }^{7,40} \mathrm{ZrO}_{2},{ }^{8,41} \mathrm{HfO}_{2}{ }^{9,23,42,43}$ $\mathrm{PbS},{ }^{44} \mathrm{Co},{ }^{45} \mathrm{Ni}^{27}{ }^{27}{ }^{28}{ }^{28} \mathrm{Ir}^{34,46,47}$ and $\mathrm{Pt}^{48,9,42,45}$ has been demonstrated by area deactivation using various types of SAMs. Photochemical induced atomic layer deposition of $\mathrm{Al}_{2} \mathrm{O}_{3}$ has been used to demonstrate AS-ALD of $\mathrm{Al}_{2} \mathrm{O}_{3} \cdot{ }^{50}$ Recently, an ultrathin ion-implanted $\mathrm{CF}_{x}$ layer has been demonstrated to be an effective deactivation material for Pt ALD growth process. ${ }^{51}$ Certain polymers such as PMMA, PVP, and polyimide have also been used as area deactivating agents to block ALD growth processes. Area-selective ALD of $\mathrm{TiO}_{2},{ }^{29,31,52} \mathrm{CeO}_{2},{ }^{53} \mathrm{ZnO},{ }^{54}$ $\mathrm{N}$ doped $\mathrm{ZnO},{ }^{55} \mathrm{Ru}^{29,56} \mathrm{Rh}^{57} \mathrm{Ir}^{29,56}$ and $\mathrm{Pt}^{29,56,39,58}$ have been demonstrated using polymer blocking layers. If ALD grown films start nucleating on these patterned polymer layers, conventional lift-off process is utilized to achieve the desired patterning. $\mathrm{Al}_{2} \mathrm{O}_{3}{ }^{29,56,59} \mathrm{TiO}_{2},{ }^{60} \mathrm{ZnO},{ }^{61,62} \mathrm{ZrO}_{2},{ }^{56,57} \mathrm{HfO}_{2}{ }^{60}$ $\mathrm{CeO}_{2},{ }^{63}$ and $\mathrm{Co}^{45}$ films have been patterned using polymers as lift-off resist layers. PMMA has also been utilized as a chemical sponge in sequential infiltration synthesis (SIS) technique to achieve AS-ALD of $\mathrm{Al}_{2} \mathrm{O}_{3} .{ }^{64}$ Selective ALD on porphyrins has been reported as an alternative approach to grow isolated metal oxide islands that are spatially separated. ${ }^{65}$ Recently, selective growth of $\mathrm{TiN}$ on $\mathrm{HfO}_{2}$ across nanolines and nanopillars has been demonstrated. ${ }^{66}$ SAMs form defects at regions of high curvature, allowing nucleation of TiN films in ALD. On the other hand, SAMs grown on planar surfaces exhibited complete blocking of TiN up to a certain limit of ALD cycles.

Nevertheless, several constraints are associated with the ASALD processes relying on area-deactivation. It is essential to have large-area defect-free coverage of SAMs for effective deactivation. Formation of a high-quality SAM with almost no defects is challenging and usually takes more than $24 \mathrm{~h}$ to obtain relatively densely packed hydrophobic SAM coverage without microscopic pin holes ${ }^{5,10,38,47,49}$ Samples are immersed in a SAM solution for such a long time to enhance the packing density. Additionally, head groups must be chemically bonded to the surface of the substrate and it introduces a limitation for selection of substrates for which such bonding will occur. ${ }^{51}$ Controlling the dimensions of patterning is yet another issue for AS-ALD processes involving SAMs. As a typical SAM is only $\sim 2 \mathrm{~nm}$ thick, it is quite challenging to fabricate thicker features more than a few nanometers. ${ }^{10}$ Once the film thickness increases above the height of SAM, lateral film overgrowth might start. On the other hand, polymer films are usually deposited using spin coating, which is a rather in-efficient and low throughput coating technique. Moreover, both SAMs and polymers are solution-based processes which implies that their applicability with patterning on 3D nanostructures will not be straightforward. Finally, solution-based processes also limit integrability of SAMs and polymers with the thin film processes carried out in vacuum reactors.

These restrictions pose serious limitations for successful integration of area-selective ALD processes for nanoscale device fabrication. Overcoming these issues require alternate approaches featuring significantly less process complexity. Only then AS-ALD might attain as serious process alternative for high-volume manufacturing. Toward this goal, in this study, we present a new strategy to achieve selective deposition by using inductively coupled plasma (ICP) polymerized fluorocarbon deactivation layer against metal-oxide ALD processes. Plasma polymerized fluorocarbon layer was grown in an ICP reactor using $\mathrm{C}_{4} \mathrm{~F}_{8}$ feed gas. The relatively fast and conformal deposition of the fluorocarbon layer $(\sim 30-35 \mathrm{~nm} / \mathrm{min})$ provides a strong advantage against SAMs and spin-coated polymer blocking layers. This strategy provides another distinct advantage; as the growth of fluorocarbon blocking layer is performed in a vacuum reactor, it allows for easy integration with ALD reactors. A relatively easy thickness control of fluorocarbon layer would possibly solve the issue of lateral broadening. An additional merit of such an approach would be to achieve topographical selectivity due to relatively conformal growth of fluorocarbon layer which might enable patterning on 3D structures. All these advantages combined with the efficient gaseous precursor $\left(\mathrm{C}_{4} \mathrm{~F}_{8}\right)$ usage in vapor phase deposition process make this approach attractive to explore.

In this work, we test the effectiveness of ICP polymerized fluorocarbon layer as a hydrophobic surface to inhibit nucleation and growth of $\mathrm{ZnO}, \mathrm{HfO}_{2}$, and $\mathrm{Al}_{2} \mathrm{O}_{3}$. The hydrophobic fluorocarbon layer is characterized by $\mathrm{X}$-ray photoelectron spectroscopy (XPS), static contact angle, and spectroscopic ellipsometer measurements. Metal-oxide ALD growth of different cycles have been performed on fluorocarbon/Si and bare $\mathrm{Si}(100)$ substrates. Contact angle, spectroscopic ellipsometer, XPS, and scanning electron microscopy (SEM) measurements were performed to investigate the blocking ability of fluorocarbon layer against ALDgrown metal-oxides. Finally, $\mathrm{ZnO}$ was grown on lithographically defined patterns of fluorocarbon layer; High resolution SEM (HR-SEM) and XPS line scan were performed to demonstrate successful $\mathrm{ZnO}$ patterning via AS-ALD.

\section{EXPERIMENTAL SECTION}

Film Growth. As a proof of concept hydrophobic inhibition layer to demonstrate AS-ALD, fluorocarbon was coated by plasma polymerization using ICP etching reactor with $\mathrm{C}_{4} \mathrm{~F}_{8}$ gas line, normally used to execute deep reactive ion etching (DRIE) recipes for $\mathrm{Si}$ etch processes. Deposition of fluorocarbon was performed for $70 \mathrm{~s}$ using $\mathrm{C}_{4} \mathrm{~F}_{8}$ gas flow rate of $70 \mathrm{sccm}$. A plasma power of $400 \mathrm{~W}$ was employed and growth was performed at room temperature. For preparation of reference control samples, $\mathrm{Si}(100)$ samples were solvent cleaned and exposed to $\mathrm{O}_{2}$ plasma for $2 \mathrm{~min}$ before metal-oxide ALD growth in order to increase the concentration of hydroxyl groups on the substrate. ${ }^{11,12} \mathrm{ZnO}, \mathrm{HfO}_{2}$, and $\mathrm{Al}_{2} \mathrm{O}_{3}$ layers were deposited by $\mathrm{ALD}$ using $\mathrm{Et}_{2} \mathrm{Zn}, \mathrm{Hf}\left(\mathrm{NMe}_{2}\right)_{4}, \mathrm{Al}\left(\mathrm{CH}_{3}\right)_{3}$, and $\mathrm{H}_{2} \mathrm{O}$ as zinc, hafnium, aluminum, and oxygen precursors, respectively. All depositions were carried out at $200{ }^{\circ} \mathrm{C}$ in Savannah S100 ALD reactor, (Ultratech/CambridgeNanotech Inc.) using $\mathrm{N}_{2}$ as the carrier and purge gas. One growth cycle of $\mathrm{ZnO}$ consisted of $\mathrm{Et}_{2} \mathrm{Zn}$ pulse $(0.015 \mathrm{~s}), \mathrm{N}_{2}$ purge $(10 \mathrm{~s}), \mathrm{H}_{2} \mathrm{O}$ pulse $(0.015 \mathrm{~s})$, and $\mathrm{N}_{2}$ purge $(10 \mathrm{~s})$. One growth cycle of $\mathrm{HfO}_{2}$ consisted of $\mathrm{Hf}\left(\mathrm{NMe}_{2}\right)_{4}$ pulse $(0.2 \mathrm{~s}), \mathrm{N}_{2}$ purge $(15 \mathrm{~s})$, $\mathrm{H}_{2} \mathrm{O}$ pulse $(0.015 \mathrm{~s})$, and $\mathrm{N}_{2}$ purge $(10 \mathrm{~s}) . \mathrm{Hf}\left(\mathrm{NMe}_{2}\right)_{4}$ was preheated to $75{ }^{\circ} \mathrm{C}$ and stabilized at this temperature prior to depositions. One growth cycle of $\mathrm{Al}_{2} \mathrm{O}_{3}$ consisted of $\mathrm{Al}\left(\mathrm{CH}_{3}\right)_{3}$ pulse $(0.015 \mathrm{~s}), \mathrm{N}_{2}$ purge $(8 \mathrm{~s}), \mathrm{H}_{2} \mathrm{O}$ pulse $(0.015 \mathrm{~s})$, and $\mathrm{N}_{2}$ purge ( $8 \mathrm{~s})$.

Film Characterization and Patterning. Contact angle of bare and fluorocarbon layer coated substrates have been 
measured before and after ALD growth sessions using static contact angle measurement setup (OCA 30). A water drop of 4 $\mu \mathrm{L}$ was dropped on the samples surface to measure the contact angle. Film thicknesses have been determined using a variable angle spectroscopic ellipsometer (V-VASE, J.A. Woollam Co. Inc., Lincoln, NE) which is coupled with rotating analyzer and xenon light source. The ellipsometric spectra were collected at three angles of incidence $\left(65^{\circ}, 70^{\circ}\right.$, and $\left.75^{\circ}\right)$ to yield adequate sensitivity over the full spectral range. Film thickness values were extracted by fitting the spectroscopic ellipsometer data using Cauchy model, while substrate was taken as default $\mathrm{Si}(100)$ in V-Vase Woollam software. Elemental composition and chemical bonding states of the metal-oxide thin films were obtained by XPS measurements using Thermo Scientific KAlpha spectrometer (Thermo Fisher Scientific, Waltham, MA) with a monochromatized $\mathrm{Al} \mathrm{K} \alpha \mathrm{X}$-ray source (spot size $\sim 400$ $\mu \mathrm{m}$ ). All peaks in XPS survey scans are referenced to C 1s peak for charge correction and quantification of survey scans have been performed using Avantage software. Surface morphologies of the $\mathrm{ZnO}$ thin films were determined using FIB SEM (FIB system (FEI Nova 600i Nanolab). In order to pattern fluorocarbon layer via photolithography on the Silicon wafer, $1.4 \mu \mathrm{m}$ of $\mathrm{AZ} 5214$ photoresist is spun on the wafer and is exposed to UV light under a photomask to be developed into checker board and line patterns. The wafer is hard baked at 110 ${ }^{\circ} \mathrm{C}$ for $5 \mathrm{~min}$. A thin layer of fluorocarbon is then deposited in the ICP reactor. Once the deposition is complete, the wafer is dipped in acetone to liftoff the fluorocarbon layer from undesired regions. The wafer is solvent-cleaned before $\mathrm{ZnO}$ growth. XPS line scan was performed on patterned $\mathrm{ZnO}$ sample using the same XPS system with an X-ray spot size of $100 \mu \mathrm{m}$.

\section{RESULTS AND DISCUSSION}

A $\sim 32 \mathrm{~nm}$ thick plasma polymerized fluorocarbon layer was deposited on $\mathrm{Si}(100)$ using ICP reactor. The polymer film is believed to be formed by the plasma fragmentation of $\mathrm{C}_{4} \mathrm{~F}_{8}$ monomers into $\mathrm{CF}_{\mathrm{X}}$ radicals resulting in the polymer deposition. ${ }^{62,63}$ Elemental composition and chemical bonding states of plasma polymerized fluorocarbon layer deposited on $\mathrm{Si}(100)$ was first investigated by XPS. The spectrum of XPS survey scan and high resolution scans of fluorine and carbon are presented in Figure 1. Survey scan (Figure 1a) revealed the presence of $\mathrm{F} 1 \mathrm{~s}, \mathrm{C} 1 \mathrm{~s}$, and $\mathrm{O} 1 \mathrm{~s}$ peaks having relative atomic concentrations of $54.51 \%, 43.91 \%$, and $1.57 \%$, respectively. The fluorine to carbon ratio $(\mathrm{F} / \mathrm{C})$ is found to be 1.24. Larger fragments produced by the dissociation of $\mathrm{C}_{4} \mathrm{~F}_{8}$ are responsible for polymer film formation and unsaturated fragments (low $\mathrm{F}$ :C ratios) promote cross-linking of the polymer film. ${ }^{67,68}$ Chemical bonding states in the polymer film were studied by the evaluation of F 1s and C 1s HR-XPS scans and are presented in Figure 1, parts b and c. HR-XPS Scan of F 1s spectrum shows a single symmetric peak at $689.73 \mathrm{eV}$ which corresponds to $\mathrm{C}-\mathrm{F}$ covalent bond. HR-XPS scan of $\mathrm{C} 1 \mathrm{~s}$ shows various bonding schemes which are assigned to different chemical states (Figure 1c). C 1s HR-XPS spectra has been deconvoluted into four sub peaks, which are assigned to $\mathrm{C}-\mathrm{CF}(288.50 \mathrm{eV}), \mathrm{CF}(290.77$ $\mathrm{eV}), \mathrm{CF}_{2}(292.80 \mathrm{eV})$, and $\mathrm{CF}_{3}(294.60 \mathrm{eV})$ components. ${ }^{68}$ The ability of the plasma polymerized fluorocarbon layer to block deposition against $\mathrm{ZnO}, \mathrm{HfO}_{2}$, and $\mathrm{Al}_{2} \mathrm{O}_{3} \mathrm{ALD}$ was evaluated next by performing contact angle, XPS, spectroscopic ellipsometer, and HR-SEM measurements. As reference control sample, metal oxide films were also grown simultaneously on $\mathrm{O}_{2}$ plasma treated $\mathrm{Si}(100)$. The purpose of predeposition $\mathrm{O}_{2}$
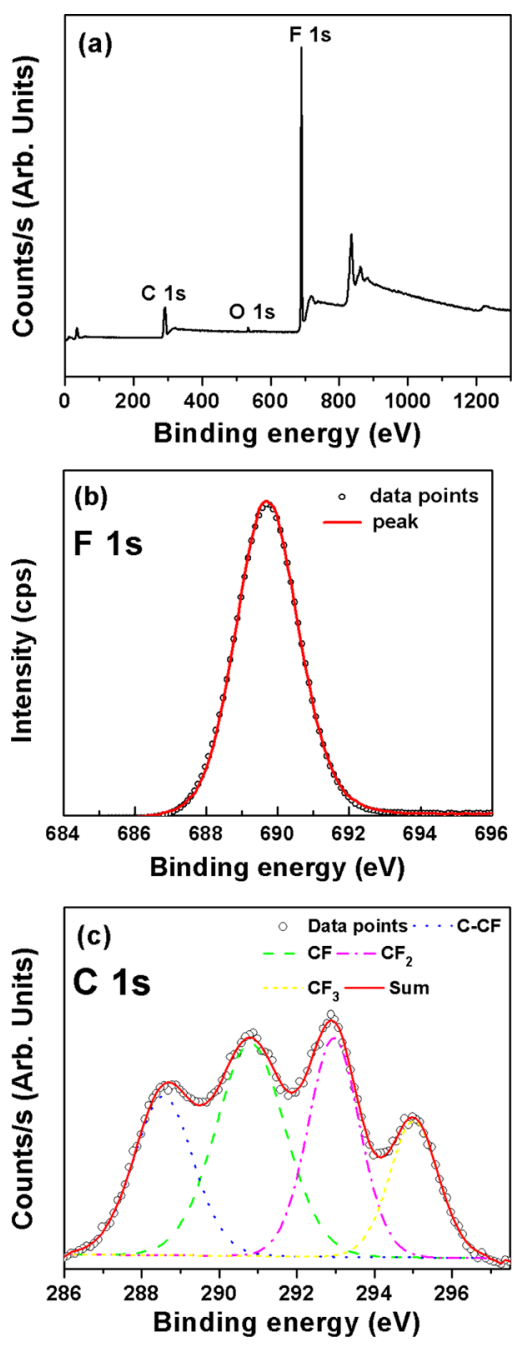

Figure 1. (a) XPS survey scan obtained from a $232 \mathrm{~nm}$ thick plasma polymerized fluorocarbon thin film deposited on $\mathrm{Si}(100)$. High resolution XPS scans of (b) F 1s and (c) C 1s obtained from the same film.

plasma treatment was to impart high concentration of $\mathrm{OH}$ groups on $\mathrm{Si}$, which are well-known to prevent nucleation delay at the initial stages of ALD growth. ${ }^{12}$

Figure 2 a shows the variation in contact angle of $\mathrm{Si}(100)$ and fluorocarbon/Si surfaces with the increase in $\mathrm{ZnO}$ ALD growth cycles. The contact angle of bare fluorocarbon/Si was measured as $114^{\circ}$ which indicates the hydrophobic nature of grown polymer film. On the other hand, contact angle of bare $\mathrm{Si}(100)$ was measured as $71^{\circ}$. The contact angle of fluorocarbon/Si film does not change noticeably until 136 growth cycles of $\mathrm{ZnO}$. After 102 growth cycles of $\mathrm{ZnO}$ on fluorocarbon/Si(100), contact angle was measured as $110.5^{\circ}$ which decreases to $104.2^{\circ}$ after 136-cycle growth. This slight decrease of contact angle suggests the onset of $\mathrm{ZnO}$ nucleation on fluorocarbon/Si after 136 cycles of $\mathrm{ZnO}$ growth. With further increase in growth cycles from 136 to 202, the contact angle decreases remarkably and falls down to $64^{\circ}$. This result shows that $\mathrm{ZnO}$ growth initiates around $136 \mathrm{ALD}$ cycles due to degradation of the hydrophobic nature of fluorocarbon polymer layer. On the contrary, the contact angle of $\mathrm{Si}$ surface changes from $71^{\circ}$ to $49^{\circ}$ when exposed to 34 cycles of $\mathrm{ZnO}$ growth and remains stable until 202 growth cycles where it exhibits a slight increase. Figure $2 \mathrm{~b}$ shows the change in $\mathrm{ZnO}$ thickness with the increase 

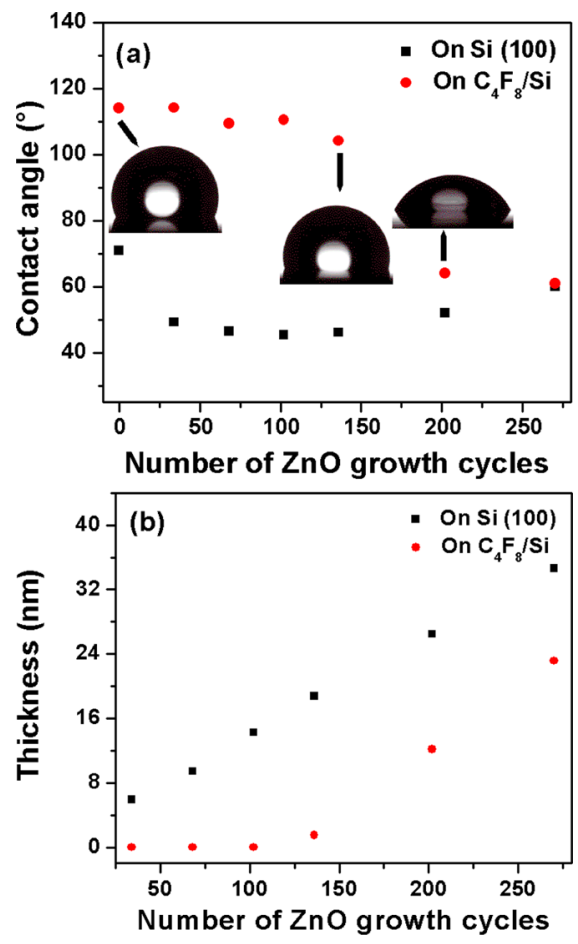

Figure 2. Variation in contact angle (a) and thickness (b) of $\mathrm{ZnO}$ with the increase in number of growth cycles on $\mathrm{Si}(100)$ and fluorocarbon/ Si.

in number of growth cycles on $\mathrm{Si}(100)$ and fluorocarbon/Si. Thickness of $\mathrm{ZnO}$ increases linearly after nucleation onset with the increase in number of growth cycles which is typically observed for ALD processes. The growth per cycle (GPC) of $\mathrm{ZnO}$ on $\mathrm{Si}(100)$ is measured as $\sim 1.3-1.4 \AA$. On fluorocarbon/ $\mathrm{Si}$, no growth of $\mathrm{ZnO}$ is observed until 102 ALD cycles while a very thin layer of $\sim 1.5 \mathrm{~nm} \mathrm{ZnO}$ was measured after the 136th cycle. With further increase in growth cycles, the growth rate of $\mathrm{ZnO}$ on fluorocarbon/Si becomes similar as on bare $\mathrm{Si}(100)$. The ellipsometer measurements are consistent with the contact angle measurements, which confirms $\mathrm{ZnO}$ growth inhibition on fluorocarbon/ $\mathrm{Si}(100)$ up to $102 \mathrm{ALD}$ growth cycles.

To confirm the $\mathrm{ZnO}$ blocking ability of plasma polymerized fluorocarbon layer, XPS measurements (Figure 3) were conducted on $\mathrm{Si}(100)$ and fluorocarbon/Si substrates exposed with different number of ALD cycles. Survey scans from the surface of $\mathrm{ZnO}$ films grown on $\mathrm{Si}(100)$ (Figure 3a) indicated the presence of zinc, oxygen, and carbon with $\mathrm{Zn} 2 \mathrm{p} 3, \mathrm{O} 1 \mathrm{~s}$, and $\mathrm{C}$ 1s peaks, respectively. $\mathrm{ZnO}$ samples with different number of ALD cycles on $\mathrm{Si}(100)$ reveal the same peaks of $\mathrm{Zn}$ 2 p3, O 1s, and C 1s. Figure $3 \mathrm{~b}$ shows the XPS survey scans obtained from fluorocarbon coated substrates exposed to ALD growth cycles starting from 34 up to 270 . Only F 1s and C 1s peaks are observed until 102 growth cycles which are originating from the plasma polymerized fluorocarbon layer. Although no $\mathrm{Zn}$ signal was observed up to 102 cycles, a small $\mathrm{Zn}$ signal appeared at 136 cycles confirming the initiation of $\mathrm{ZnO}$ growth on fluorocarbon/Si. A meaningful $\mathrm{Zn} 2 \mathrm{p} 3$ peak begins to appear with 202 ALD cycles and remains stable for further growth cycles. The fact that $\mathrm{F}$ 1s peak disappears abruptly after $136 \mathrm{ZnO}$ ALD cycles supports the nucleation onset.

These results further verify the contact angle and ellipsometer measurements and show that $\mathrm{ZnO}$ growth initiates
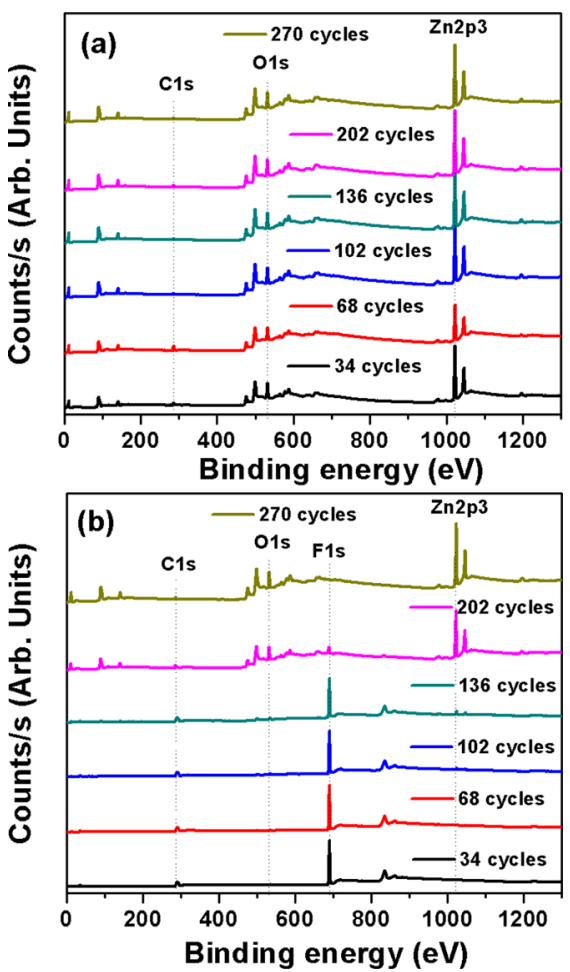

Figure 3. XPS survey scans of $\mathrm{ZnO}$ grown with different number of ALD cycles on (a) $\mathrm{Si}(100)$ and (b) fluorocarbon/Si revealing presence of different elements.

around 136 ALD cycles and that plasma polymerized fluorocarbon layer is effectively blocking $\mathrm{ZnO}$ growth up to $\sim 130$ ALD cycles. Table 1 provides a direct comparison of

Table 1. Variation in $\mathrm{Zn}$ at. \% with the Increase in Number of $\mathrm{ZnO}$ Growth Cycles on $\mathrm{Si}(100)$ and Fluorocarbon/Si

\begin{tabular}{ccc} 
no. of growth cycles & $\mathrm{Zn}$ at. \% on fluorocarbon/Si & $\mathrm{Zn}$ at. \% on $\mathrm{Si}(100)$ \\
34 & - & 31.28 \\
68 & - & 24.2 \\
102 & - & 36.3 \\
136 & 1.62 & 37.02 \\
202 & 24.72 & 37.54 \\
270 & 37.58 & 37.89 \\
\hline
\end{tabular}

atomic percentages (at. \%) of $\mathrm{Zn}$ from $\mathrm{ZnO}$ grown on $\mathrm{Si}(100)$ and fluorocarbon/Si which are evaluated from the quantification of XPS survey scans. A notable rise in $\mathrm{Zn}$ at. \% is observed only after $136 \mathrm{ZnO}$ ALD growth cycles on fluorocarbon/Si. Zn at. \% remains steady at a value around $\sim 36-37$ at. $\%$ on $\mathrm{ZnO} /$ $\mathrm{Si}$ with zinc to oxygen ratio $(\mathrm{Zn} / \mathrm{O})$ of $\sim 0.86-0.88$.

High resolution XPS scans of $\mathrm{Zn} 2 \mathrm{p}_{3 / 2}$ state have been acquired to extract the formed bonding configuration and verification of XPS survey scans. Figure 4 shows the HR-XPS $\mathrm{Zn} 2 \mathrm{p}_{3 / 2}$ scans obtained from $\mathrm{ZnO}$ grown on fluorocarbon/Si with different number of growth cycles. No clear peak is observed for $\mathrm{Zn} 2 \mathrm{p}_{3 / 2}$ scan up to 102 ALD cycles, while a weak and rather broad peak is observed for 136 growth cycles of $\mathrm{ZnO}$ on fluorocarbon/Si. There is a drastic increase in $\mathrm{Zn} 2 \mathrm{p}_{3 / 2}$ peak intensity as the number of growth cycles reach 202 . Indeed a clear well-established $\mathrm{Zn} 2 \mathrm{p}_{3 / 2}$ peak is observed at $202 \mathrm{nd}$ and 270th ALD cycles on fluorocarbon/Si. This peak is observed at a binding energy value of $1022.12 \mathrm{eV}$ and corresponds to the 


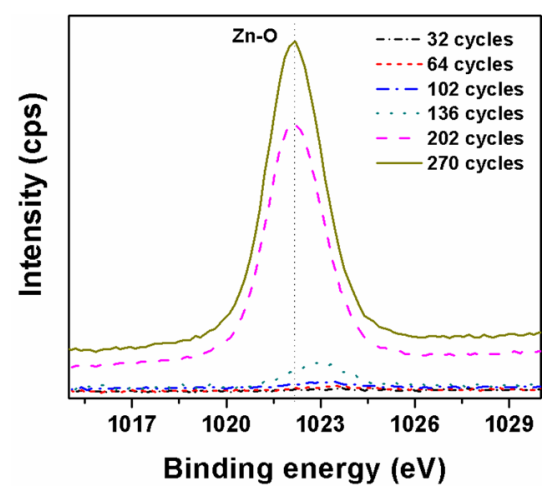

Figure 4. HR-XPS scans of $\mathrm{Zn} 2 \mathrm{p}_{3 / 2}$ obtained from $\mathrm{ZnO}$ grown on fluorocarbon/ $\mathrm{Si}$ as a function of ALD growth cycles.

$\mathrm{Zn}-\mathrm{O}$ bond. ${ }^{69}$ These results show excellent correlation with all the characterization results provided so far.

SEM imaging was performed to observe the surface morphology of $\mathrm{ZnO}$ grown on $\mathrm{Si}$ and fluorocarbon/Si. Parts $\mathrm{a}$ and $\mathrm{b}$ of Figure S1 show the SEM images of bare fluorocarbon/Si and $\mathrm{ZnO}$ grown on fluorocarbon/Si with 68 number of growth cycles, respectively. These SEM images reveal the uniform surface morphology of fluorocarbon layer and illustrate no observable growth of $\mathrm{ZnO}$ on fluorocarbon/Si after 68 growth cycles. Parts a and b ofFigure 5 show the SEM

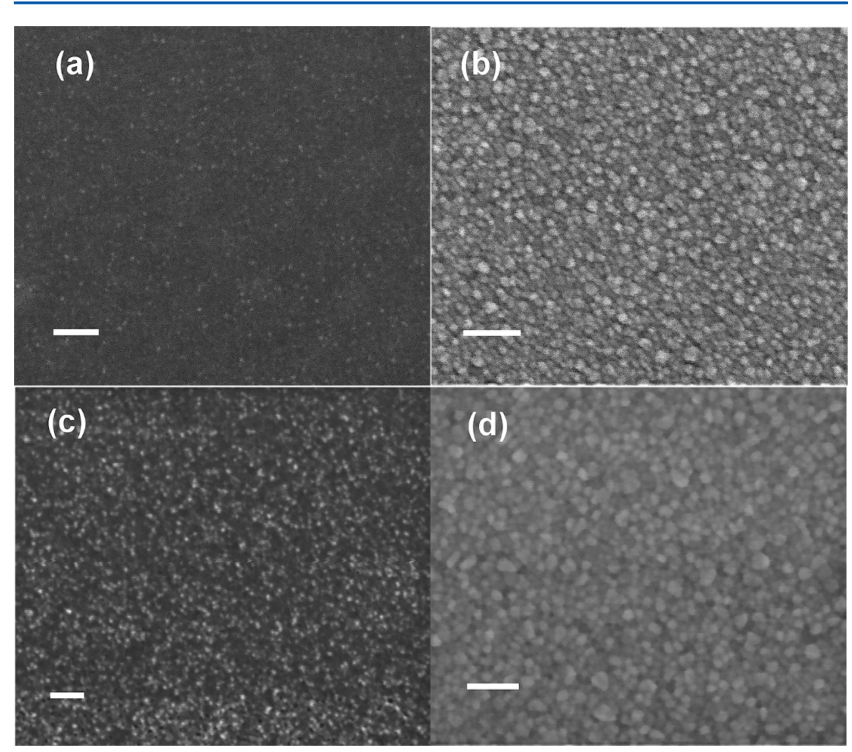

Figure 5. Plan view SEM images of 102 cycles ALD grown $\mathrm{ZnO}$ on (a) fluorocarbon/Si and (b) $\mathrm{Si}(100) ; 136$ cycles ALD grown $\mathrm{ZnO}$ on (c) fluorocarbon $/ \mathrm{Si}$ and (d) $\mathrm{Si}(100)$ (all scale bars $=50 \mathrm{~nm}$ ).

images of $\mathrm{ZnO}$ grown with 102 cycles of growth on fluorocarbon/Si and $\mathrm{Si}(100)$, respectively. Very few $\mathrm{ZnO}$ nuclei begin to form on fluorocarbon/Si surface after 102 ALD cycles, while the grainy structure of $\mathrm{ZnO}$ is clearly visible on $\mathrm{Si}(100)$ with the same number of $\mathrm{ZnO}$ growth cycles. As XPS did not detect any $\mathrm{ZnO}$ on fluorocarbon/Si up to 102 cycles, the observed $\mathrm{ZnO}$ nuclei might possibly be below the detection limit of XPS. Parts $\mathrm{c}$ and d of Figure 5 show the SEM images of 136-cycle $\mathrm{ZnO}$ on fluorocarbon/Si and $\mathrm{Si}$. The quantity of $\mathrm{ZnO}$ nuclei notably increased after 136 growth cycles on fluorocarbon/Si with significantly larger areal coverage, while relatively larger grains are observed on its counterpart $\mathrm{ZnO}$ on $\mathrm{Si}(100)$. On the basis of contact angle, spectroscopic ellipsometer, XPS, and SEM measurements presented above, we conclude that plasma-polymerized fluorocarbon layer is effective in blocking $\mathrm{ZnO}$ growth up to more than 100 ALD cycles.

We have also investigated the blocking/inhibition ability of plasma-polymerized fluorocarbon layer against other metal oxide materials including $\mathrm{HfO}_{2}$ and $\mathrm{Al}_{2} \mathrm{O}_{3}$. $\mathrm{HfO}_{2}$ and $\mathrm{Al}_{2} \mathrm{O}_{3}$ growth have been performed in the same reactor with thermal ALD using various number of ALD cycles on plasma polymerized fluorocarbon layer coated on $\mathrm{Si}(100)$ and on bare $\mathrm{Si}(100)$ substrates. Contact angle, spectroscopic ellipsometer, and XPS measurements have similarly been performed to investigate the $\mathrm{HfO}_{2}$ and $\mathrm{Al}_{2} \mathrm{O}_{3}$ growth selectivity on plasma polymerized fluorocarbon layer. Figure 6 shows the contact
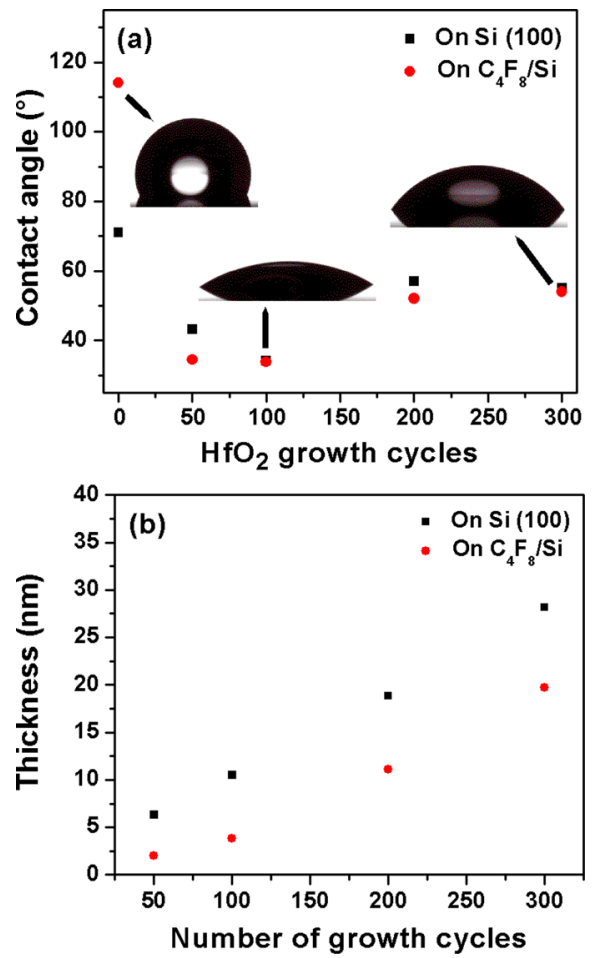

Figure 6. Variation in (a) contact angle and (b) thickness of $\mathrm{HfO}_{2}$ as a function of ALD growth cycles on $\mathrm{Si}(100)$ and fluorocarbon/Si.

angle and thickness variation of ALD grown $\mathrm{HfO}_{2}$ on fluorocarbon/ $\mathrm{Si}(100)$ and $\mathrm{Si}(100)$ as a function of total number of growth cycles. Both $\mathrm{Si}(100)$ and fluorocarbon/Si show an abrupt decrease in contact angle (Figure 6a) after 50 cycles of $\mathrm{HfO}_{2}$ growth. A slight increase in contact angle is observed for 100 cycles of $\mathrm{HfO}_{2}$ growth on $\mathrm{Si}(100)$ and fluorocarbon/Si and then it becomes nearly constant for both the substrates. Figure $6 \mathrm{~b}$ shows change in thickness of ALD grown $\mathrm{HfO}_{2}$ on fluorocarbon/Si and $\mathrm{Si}(100)$ with the increase in number of growth cycles. The thickness of $\mathrm{HfO}_{2}$ on $\mathrm{Si}(100)$ increases linearly with the increase in number of growth cycles and the GPC is measured as $\sim 0.95-1.00 \AA$. On the other hand, the growth rate of $\mathrm{HfO}_{2}$ is substantially less on fluorocarbon/Si in the first 100 cycles of growth in contrast with $\mathrm{Si}(100)$. With the increase in number of cycles beyond 100, GPC of $\mathrm{HfO}_{2}$ on fluorocarbon/Si becomes similar as on $\mathrm{Si}(100)$. It is evident from Figure $6 \mathrm{~b}$ that the slope of $\mathrm{HfO}_{2}$ thickness increase (GPC) on fluorocarbon/Si is less up to 100 cycles while it 
increases beyond that and becomes same as GPC on $\mathrm{Si}(100)$. These results reveal that initial nucleation of $\mathrm{HfO}_{2}$ is considerably slower on fluorocarbon/Si up to 100 cycles, where GPC equals the GPC on bare Si surface after sufficient coverage of $\mathrm{HfO}_{2}$ is achieved.

XPS measurements are conducted on $\mathrm{HfO}_{2}$ grown on $\mathrm{Si}(100)$ and fluorocarbon $/ \mathrm{Si}(100)$ and recorded survey scans are presented in Figure S2, parts a and b, which indicate the presence of $\mathrm{Hf} 4 \mathrm{f}, \mathrm{C} 1 \mathrm{~s}$, and $\mathrm{O} 1 \mathrm{~s}$ peaks from $\mathrm{HfO}_{2}$ grown on both substrate surfaces. However, peak intensity of $\mathrm{Hf} 4 \mathrm{f}$ obtained from $\mathrm{HfO}_{2}$ grown with 50 cycles on fluorocarbon $/ \mathrm{Si}$ is notably lower than the corresponding peak seen on $\mathrm{Si}(100)$ with same number of growth cycles.

Atomic percentages obtained from quantification of these survey scans are provided in Table S1. These results verify the contact angle and ellipsometer measurements results and confirm that $\mathrm{HfO}_{2}$ nucleation is relatively slower on fluorocarbon/Si within the initial growth cycles.

A similar set of experiments have been conducted for $\mathrm{Al}_{2} \mathrm{O}_{3}$ grown on fluorocarbon/Si and $\mathrm{Si}(100)$. Figure 7 shows the
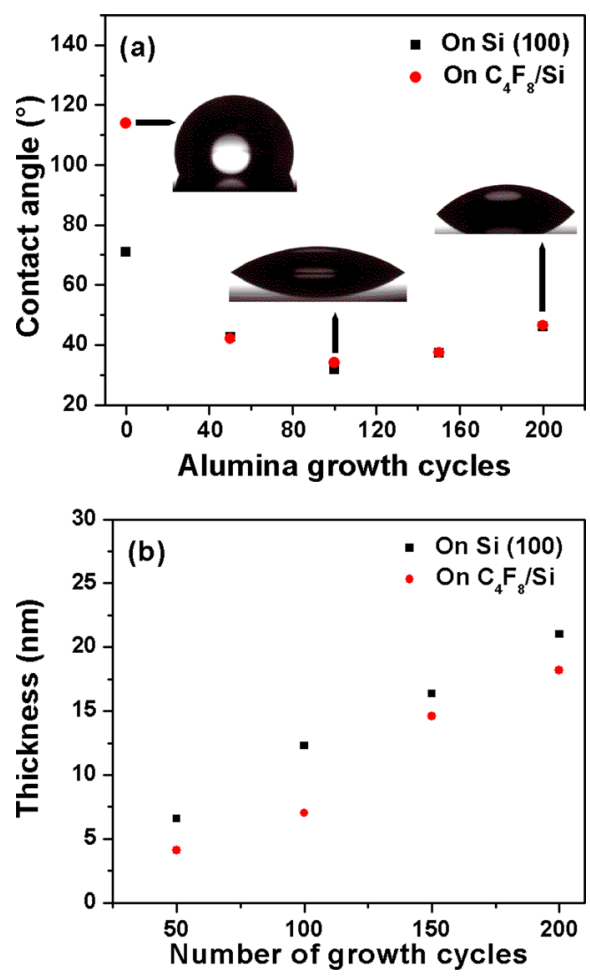

Figure 7. Variation in (a) contact angle and (b) thickness of $\mathrm{Al}_{2} \mathrm{O}_{3}$ with the increase in number of growth cycles on $\mathrm{Si}(100)$ and fluorocarbon/Si.

variation of contact angle and thickness with the number of ALD growth cycles on both substrates. In contrary to $\mathrm{ZnO}$ and $\mathrm{HfO}_{2}$, an immediate sharp decrease in contact angle has been observed for $\mathrm{Al}_{2} \mathrm{O}_{3}$ on both fluorocarbon/Si and $\mathrm{Si}(100)$, stabilizing at a value of $\sim 37-45^{\circ}$. A direct relation in alumina thickness and number of ALD cycles can be noticed from Figure $7 \mathrm{~b}$ with an alumina GPC slightly less on fluorocarbon/Si then on $\mathrm{Si}(100)$. XPS measurements have been conducted on $\mathrm{Al}_{2} \mathrm{O}_{3}$ grown on fluorocarbon/Si and $\mathrm{Si}(100)$ and survey scans have been presented in Figure S3, parts a and b. Al 2p, C 1s, and $\mathrm{O} 1 \mathrm{~s}$ peaks have been observed from films grown on both substrates. Al quantification from these survey scans have been presented in Table S2, which shows a significant presence of Al on all the substrates. These results support the observations of contact angle and spectroscopic ellipsometer measurements and reveal that the plasma-polymerized fluorocarbon layer is rather ineffective in blocking alumina growth. It has been observed that blocking ability of a particular layer for successful AS-ALD might depend on ALD processing conditions such as precursor employed, working pressure, purge time, and substrate temperature. ${ }^{10,29,52,70-72}$ In addition to ALD processing conditions, blocking capability of the fluorocarbon layer may also depend on plasma polymerization conditions such as plasma energy, working pressure, and flow rate of feed gas. Although the plasma-polymerized fluorocarbon layer shows a superior growth blocking/inhibition feature for the $\mathrm{ZnO} A L D$ process, it may further be optimized along with ALD process conditions in order to achieve growth selectivity for $\mathrm{HfO}_{2}$ and $\mathrm{Al}_{2} \mathrm{O}_{3}$ as well. Moreover, the achieved maximum number of ALD cycles before $\mathrm{ZnO}$ nucleation takes over might be further extended with a systematic study in which ICP polymerization and ALD process conditions are optimized.

After demonstrating the ability of plasma polymerized fluorocarbon layer to inhibit $\mathrm{ZnO}$ ALD growth, the next step was to employ fluorocarbon layer for patterning of ALD grown $\mathrm{ZnO}$. Photolithography was used to prepare bare $\mathrm{Si}$ and fluorocarbon/Si checkerboard and line pattern structures in a sequential manner. Figure 8a shows a plan-view SEM image of 102 cycle $\mathrm{ZnO} \mathrm{ALD}$ grown on fluorocarbon layer line patterns. The darker squares represent the areas where fluorocarbon layer is present, while bright areas represent the $\mathrm{ZnO}$ grown surface. Inset of Figure 8a shows the HR-SEM image from the interface of dark and bright areas, which reveals the grainy structure of $\mathrm{ZnO}$ only from fluorocarbon uncoated area while negligible $\mathrm{ZnO}$ grains were observed on fluorocarbon layer. Similarly, Figure $8 \mathrm{~b}$ shows a plan-view SEM image of 102 cycle $\mathrm{ZnO}$ ALD grown on fluorocarbon checkerboard patterns. The HR-SEM image obtained from the interface of coated and uncoated fluorocarbon regions reveal that grainy structure of $\mathrm{ZnO}$ is only present on the bare $\mathrm{Si}$ region.

XPS line scan was performed on a $2 \mathrm{~mm}$ wide $\mathrm{ZnO}$-coated patterned fluorocarbon/Si lines. The minimum spot size of Xrays that could be utilized was $\sim 100 \mu \mathrm{m}$; therefore, patterned lines of $2 \mathrm{~mm}$ width were selected for analysis in order to gather the data from various points. A line across an area of interest is selected on the sample and the XPS gathered data along the line at various points. $\mathrm{Zn} 2 \mathrm{p}$ intensity was measured in terms of counts per second vs spatial location along the line and presented in Figure 8c. Clearly, the higher intensity of the $\mathrm{Zn} 2 \mathrm{p}$ peak is only observed at the location of the $\mathrm{ZnO}$ pattern while the intensity at other points was equal to background intensity, confirming the successful pattern placement of $\mathrm{ZnO}$.

\section{SUMMARY AND CONCLUSION}

We demonstrate a method for achieving area-selective ALD using ICP polymerized fluorocarbon layer as a hydrophobic blocking layer to inhibit ALD growth. Contact angle, spectroscopic ellipsometry, XPS, and SEM measurements were used to evaluate the capability of plasma polymerized fluorocarbon layer to inhibit metal-oxide ALD growth. Characterizations carried out revealed that effective $\mathrm{ZnO}$ blocking on fluorocarbon layer can be achieved up to more than 100 ALD cycles, resulting in selective growth of $\sim 15 \mathrm{~nm}$ thick films. Initial nucleation has been observed for 136-cycle $\mathrm{ZnO}$ films and additional ALD cycles eventually led to growth 

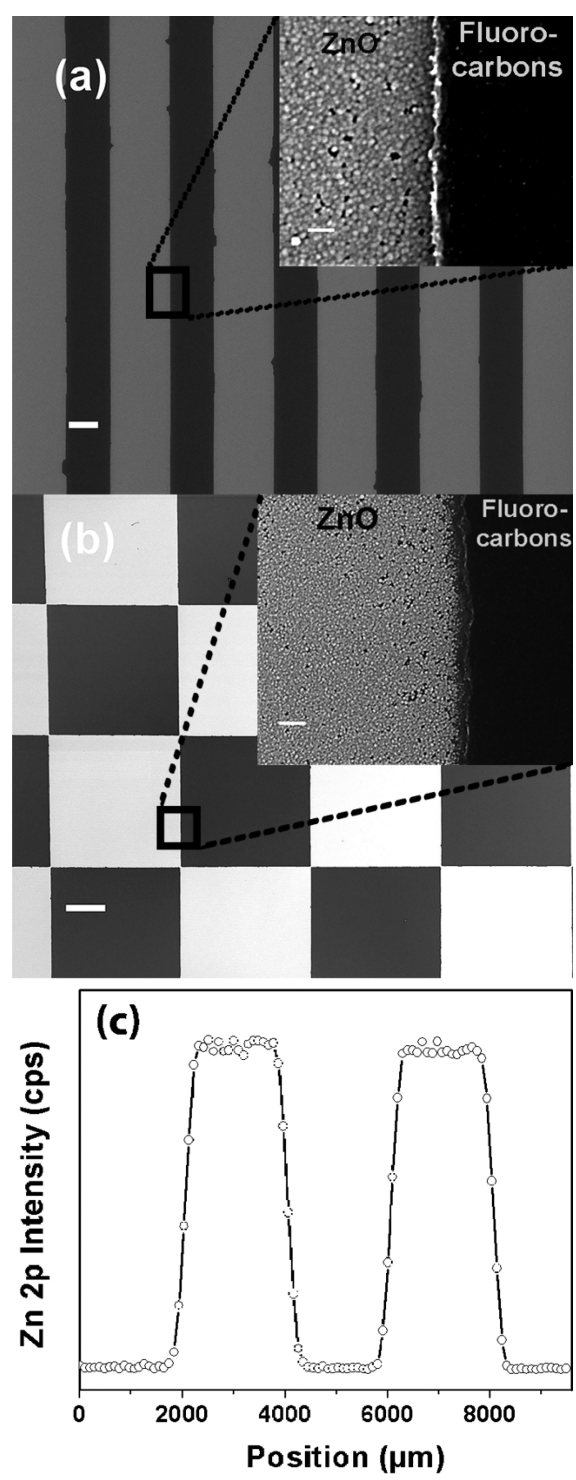

Figure 8. (a) Plan-view SEM image of 102 cycle $\mathrm{ZnO}$ ALD grown on fluorocarbon line patterns (scale bar $=10 \mu \mathrm{m}$ ) (inset) HR-SEM image from the interface of $\mathrm{ZnO}$ and fluorocarbon layer (scale bar $=50 \mathrm{~nm}$ ). (b) Plan-view SEM image of 102 cycle $\mathrm{ZnO}$ ALD grown on fluorocarbon checker board patterns (scale bar $=150 \mu \mathrm{m}$ ) (inset) HRSEM image from the interface of $\mathrm{ZnO}$ and fluorocarbon layer (scale bar $=100 \mathrm{~nm}$ ). (c) XPS line scan obtained from patterned $\mathrm{ZnO}$ substrate.

on fluorocarbon layer at conventional GPC values. On the other hand, although no complete blocking is observed, a rather slow nucleation has been observed for $\mathrm{HfO}_{2}$ growth on fluorocarbon coated surfaces up to 100 growth cycles, while the same blocking layer deposited under the present conditions has been found to be ineffective in blocking $\mathrm{Al}_{2} \mathrm{O}_{3}$ growth. By exploiting this inhibition feature of fluorocarbon layer, selfaligned $\mathrm{ZnO}$ deposition has been performed on lithographically defined patterned fluorocarbon/Si sample. High-resolution SEM images and XPS line scans confirmed the successful patterning of $\mathrm{ZnO}$ up to a film thickness of $\sim 15 \mathrm{~nm}$. The robust albeit rather simple and straightforward technique presented in this work overcomes various challenges associated with previous methods of AS-ALD and provides an alternative route toward nanopatterning using AS-ALD. Moreover, this method is expected to be implemented in achieving AS-ALD of other materials as well including metals and III-V compounds.

\section{ASSOCIATED CONTENT}

Supporting Information

The Supporting Information is available free of charge on the ACS Publications website at DOI: 10.1021/acs.jpcc.6b09406.

SEM images of bare fluorocarbon/Si sample and $\mathrm{ZnO}$ coated on fluorocarbon/Si sample with 68 cycles and, in addition, XPS survey scans of $\mathrm{HfO}_{2}$ and $\mathrm{Al}_{2} \mathrm{O}_{3}$ grown with different number of growth cycles on $\mathrm{Si}(100)$ and on fluorocarbon/Si with the quantification of hafnium and aluminum atomic percentages (PDF)

\section{AUTHOR INFORMATION}

\section{Corresponding Authors}

*(A.H.) E-mail: ali.haider@bilkent.edu.tr.

*(N.B.) E-mail: n.biyikli@aggiemail.usu.edu.

\section{Author Contributions}

The manuscript was written through contributions of all authors. All authors have given approval to the final version of the manuscript.

\section{Notes}

The authors declare no competing financial interest.

\section{ACKNOWLEDGMENTS}

The authors acknowledge the National Nanotechnology Research Center (UNAM), Bilkent University for providing the growth and materials characterization facilities. Authors also acknowledge Mr. Murat Serhatlioglu from UNAM for drawing the table of content artwork.

\section{REFERENCES}

(1) Zhang, P.; Mayer, T. S.; Jackson, T. N. 2007 IEEE Device Research Conference: Tour de Force Multigate and Nanowire Metal Oxide Semiconductor Field-Effect Transistors and Their Application. ACS Nano 2007, 1, 6-9.

(2) Biercuk, M. J.; Monsma, D. J.; Marcus, C. M.; Becker, J. S.; Gordon, R. G. Low-Temperature Atomic-Layer-Deposition Lift-off Method for Microelectronic and Nanoelectronic Applications. Appl. Phys. Lett. 2003, 83, 2405.

(3) Goldberger, J.; Hochbaum, A. I.; Fan, R.; Yang, P. Silicon Vertically Integrated Nanowire Field Effect Transistors. Nano Lett. 2006, 6, 973-977.

(4) Kim, J. M.; Lee, H. B. R.; Lansalot, C.; Dussarrat, C.; Gatineau, J.; Kim, H. Plasma-Enhanced Atomic Layer Deposition of Cobalt Using Cyclopentadienyl Isopropyl Acetamidinato-Cobalt as a Precursor. Jpn. J. Appl. Phys. 2010, 49, 05FA10.

(5) Minaye Hashemi, F. S.; Prasittichai, C.; Bent, S. F. SelfCorrecting Process for High Quality Patterning by Atomic Layer Deposition. ACS Nano 2015, 9, 8710-8717.

(6) Gay, G.; Baron, T.; Agraffeil, C.; Salhi, B.; Chevolleau, T.; Cunge, G.; Grampeix, H.; Tortai, J.-H.; Martin, F.; Jalaguier, E.; et al. CMOS Compatible Strategy Based on Selective Atomic Layer Deposition of a Hard Mask for Transferring Block Copolymer Lithography Patterns. Nanotechnology 2010, 21, 435301.

(7) Hashemi, F. S. M.; Prasittichai, C.; Bent, S. F. A New Resist for Area Selective Atomic and Molecular Layer Deposition on MetalDielectric Patterns. J. Phys. Chem. C 2014, 118, 10957-10962.

(8) Lee, J. P.; Sung, M. M. A New Patterning Method Using Photocatalytic Lithography and Selective Atomic Layer Deposition. J. Am. Chem. Soc. 2004, 126, 28-29. 
(9) Chen, R.; Bent, S. F. Chemistry for Positive Pattern Transfer Using Area-Selective Atomic Layer Deposition. Adv. Mater. 2006, 18, $1086-1090$.

(10) Mackus, A. J. M.; Bol, A. A.; Kessels, W. M. M. The Use of Atomic Layer Deposition in Advanced Nanopatterning. Nanoscale 2014, 6, 10941-10960.

(11) Profijt, H. B.; Potts, S. E.; van de Sanden, M. C. M.; Kessels, W. M. M. Plasma-Assisted Atomic Layer Deposition: Basics, Opportunities, and Challenges. J. Vac. Sci. Technol., A 2011, 29, 050801.

(12) Puurunen, R. L. Surface Chemistry of Atomic Layer Deposition: A Case Study for the Trimethylaluminum/water Process. J. Appl. Phys. 2005, 97, 121301.

(13) George, S. M. Atomic Layer Deposition: An Overview. Chem. Rev. 2010, 110, 111-131.

(14) Atanasov, S. E.; Kalanyan, B.; Parsons, G. N. Inherent SubstrateDependent Growth Initiation and Selective-Area Atomic Layer Deposition of $\mathrm{TiO}_{2}$ Using "water-Free" Metal-Halide/metal Alkoxide Reactants. J. Vac. Sci. Technol., A 2016, 34, 01A148.

(15) Kalanyan, B.; Lemaire, P. C.; Atanasov, S. E.; Ritz, M. J.; Parsons, G. N. Using Hydrogen to Expand the Inherent Substrate Selectivity Window during Tungsten Atomic Layer Deposition. Chem. Mater. 2016, 28, 117-126.

(16) Jiang, X.; Wang, H.; Qi, J.; Willis, B. G. In-Situ Spectroscopic Ellipsometry Study of Copper Selective-Area Atomic Layer Deposition on Palladium. J. Vac. Sci. Technol., A 2014, 32, 041513.

(17) McDonnell, S.; Longo, R. C.; Seitz, O.; Ballard, J. B.; Mordi, G.; Dick, D.; Owen, J. H. G.; Randall, J. N.; Kim, J.; Chabal, Y. J.; Cho, K.; Wallace, R. M. Controlling the Atomic Layer Deposition of Titanium Dioxide on Silicon: Dependence on Surface Termination. J. Phys. Chem. C 2013, 117, 20250-20259.

(18) Mackus, A. J. M.; Thissen, N. F. W.; Mulders, J. J. L.; Trompenaars, P. H. F.; Verheijen, M. A.; Bol, A. A.; Kessels, W. M. M. Direct-Write Atomic Layer Deposition of High-Quality Pt Nanostructures: Selective Growth Conditions and Seed Layer Requirements. J. Phys. Chem. C 2013, 117, 10788-10798.

(19) Mackus, A. J. M.; Mulders, J. J. L.; van De Sanden, M. C. M.; Kessels, W. M. M. Local Deposition of High-Purity Pt Nanostructures by Combining Electron Beam Induced Deposition and Atomic Layer Deposition. J. Appl. Phys. 2010, 107, 116102.

(20) Mackus, A. J. M.; Dielissen, S. A. F.; Mulders, J. J. L.; Kessels, W. M. M. Nanopatterning by Direct-Write Atomic Layer Deposition. Nanoscale 2012, 4, 4477-4480.

(21) Gupta, R.; Willis, B. G. Nanometer Spaced Electrodes Using Selective Area Atomic Layer Deposition. Appl. Phys. Lett. 2007, 90, 253102.

(22) Färm, E.; Lindroos, S.; Ritala, M.; Leskelä, M. Microcontact Printed $\mathrm{RuO}_{x}$ Film as an Activation Layer for Selective-Area Atomic Layer Deposition of Ruthenium. Chem. Mater. 2012, 24, 275-278.

(23) Liu, J.; Mao, Y.; Lan, E.; Banatao, D. R.; Forse, G. J.; Lu, J.; Blom, H. O.; Yeates, T. O.; Dunn, B.; Chang, J. P. Generation of Oxide Nanopatterns by Combining Self-Assembly of S-Layer Proteins and Area-Selective Atomic Layer Deposition. J. Am. Chem. Soc. 2008, 130, 16908-16913.

(24) Cheng, N.; Banis, M. N.; Liu, J.; Riese, A.; Li, X.; Li, R.; Ye, S.; Knights, S.; Sun, X. Extremely Stable Platinum Nanoparticles Encapsulated in a Zirconia Nanocage by Area-Selective Atomic Layer Deposition for the Oxygen Reduction Reaction. Adv. Mater. 2015, 27, 277-281.

(25) Guo, L.; Lee, I.; Zaera, F. Patterning of Solid Films via Selective Atomic Layer Deposition Based on Silylation and UV/Ozonolysis. ACS Appl. Mater. Interfaces 2016, 8, 19836-19841.

(26) Seo, E. K.; Lee, J. W.; Sung-Suh, H. M.; Sung, M. M. Atomic Layer Deposition of Titanium Oxide on Self-Assembled-MonolayerCoated Gold. Chem. Mater. 2004, 16, 1878-1883.

(27) Kim, W.-H.; Lee, H.-B.-R.; Heo, K.; Lee, Y. K.; Chung, T.-M.; Kim, C. G.; Hong, S.; Heo, J.; Kim, H. Atomic Layer Deposition of Ni Thin Films and Application to Area-Selective Deposition. J. Electrochem. Soc. 2011, 158, D1-D5.
(28) Park, K. J.; Doub, J. M.; Gougousi, T.; Parsons, G. N. Microcontact Patterning of Ruthenium Gate Electrodes by Selective Area Atomic Layer Deposition. Appl. Phys. Lett. 2005, 86, 051903.

(29) Färm, E.; Kemell, M.; Ritala, M.; Leskela, M. Selective-Area Atomic Layer Deposition Using Poly (Methyl Methacrylate) Films as Mask Layers. J. Phys. Chem. C 2008, 112, 15791-15795.

(30) Park, M. H.; Jang, Y. J.; Sung-Suh, H. M.; Sung, M. M. Selective Atomic Layer Deposition of Titanium Oxide on Patterned SelfAssembled Monolayers Formed by Microcontact Printing. Langmuir 2004, 20, 2257-2260.

(31) Hua, Y.; King, W. P.; Henderson, C. L. Nanopatterning Materials Using Area Selective Atomic Layer Deposition in Conjunction with Thermochemical Surface Modification via Heated AFM Cantilever Probe Lithography. Microelectron. Eng. 2008, 85, 934-936.

(32) Guo, L.; Qin, X.; Zaera, F. Chemical Treatment of Low-K Dielectric Surfaces for Patterning of Thin Solid Films in Microelectronic Applications. ACS Appl. Mater. Interfaces 2016, 8, 62936300.

(33) Zhang, W.; Engstrom, J. R. Effect of Substrate Composition on Atomic Layer Deposition Using Self-Assembled Monolayers as Blocking Layers. J. Vac. Sci. Technol., A 2016, 34, 01 A107.

(34) Hashemi, F. S. M.; Bent, S. F. Sequential Regeneration of SelfAssembled Monolayers for Highly Selective Atomic Layer Deposition. Adv. Mater. Interfaces 2016, 1600464.

(35) Vervuurt, R. H. J.; Sharma, A.; Jiao, Y.; Kessels, W.; Bol, A. A. Area-Selective Atomic Layer Deposition of Platinum Using Photosensitive Polyimide. Nanotechnology 2016, 27, 405302.

(36) Huang, J.; Lee, M.; Lucero, A.; Cheng, L.; Kim, J. Area-Selective ALD of $\mathrm{TiO}_{2}$ Nanolines with Electron-Beam Lithography. J. Phys. Chem. C 2014, 118, 23306-23312.

(37) Bent, S. F. Heads or Tails: Which Is More Important in Molecular Self-Assembly? ACS Nano 2007, 1, 10-12.

(38) Färm, E.; Kemell, M.; Ritala, M.; Leskelä, M. Selective-Area Atomic Layer Deposition with Microcontact Printed Self-Assembled Octadecyltrichlorosilane Monolayers as Mask Layers. Thin Solid Films 2008, 517, 972-975.

(39) Huang, J.; Lee, M.; Kim, J. Selective Atomic Layer Deposition with Electron-Beam Patterned Self-Assembled Monolayers. J. Vac. Sci. Technol., A 2012, 30, 01A128.

(40) Yan, M.; Koide, Y.; Babcock, J. R.; Markworth, P. R.; Belot, J. a.; Marks, T. J.; Chang, R. P. H. Selective-Area Atomic Layer Epitaxy Growth of $\mathrm{ZnO}$ Features on Soft Lithography-Patterned Substrates. Appl. Phys. Lett. 2001, 79, 1709-1711.

(41) Lee, W.; Prinz, F. B. Area-Selective Atomic Layer Deposition Using Self-Assembled Monolayer and Scanning Probe Lithography. J. Electrochem. Soc. 2009, 156, G125-G128.

(42) Jiang, X.; Chen, R; Bent, S. F. Spatial Control over Atomic Layer Deposition Using Microcontact-Printed Resists. Surf. Coat. Technol. 2007, 201, 8799-8807.

(43) Chen, R.; Kim, H.; McIntyre, P. C.; Porter, D. W.; Bent, S. F. Achieving Area-Selective Atomic Layer Deposition on Patterned Substrates by Selective Surface Modification. Appl. Phys. Lett. 2005, 86, 191910.

(44) Lee, W.; Dasgupta, N. P.; Trejo, O.; Lee, J. R; Hwang, J.; Usui, T.; Prinz, F. B. Area-Selective Atomic Layer Deposition of Lead Sulfide: Nanoscale Patterning and DFT Simulations. Langmuir 2010, $26,6845-6852$.

(45) Lee, H.-B.-R.; Kim, W.-H.; Lee, J. W.; Kim, J.-M.; Heo, K.; Hwang, I. C.; Park, Y.; Hong, S.; Kim, H. High Quality Area-Selective Atomic Layer Deposition Co Using Ammonia Gas as a Reactant. J. Electrochem. Soc. 2010, 157, D10-D15.

(46) Färm, E.; Vehkamäki, M.; Ritala, M.; Leskelä, M. Passivation of Copper Surfaces for Selective-Area ALD Using a Thiol Self-Assembled Monolayer. Semicond. Sci. Technol. 2012, 27, 074004.

(47) Färm, E.; Kemell, M.; Ritala, M.; Leskelä, M. Self-Assembled Octadecyltrimethoxysilane Monolayers Enabling Selective-Area Atomic Layer Deposition of Iridium. Chem. Vap. Deposition 2006, $12,415-417$. 
(48) Cao, K.; Zhu, Q.; Shan, B.; Chen, R. Controlled Synthesis of $\mathrm{Pd} / \mathrm{Pt}$ Core Shell Nanoparticles Using Area-Selective Atomic Layer Deposition. Sci. Rep. 2015, 5, 8470.

(49) Jiang, X.; Bent, S. F. Area-Selective Atomic Layer Deposition of Platinum on YSZ Substrates Using Microcontact Printed SAMs. J. Electrochem. Soc. 2007, 154, D648-D656.

(50) Chalker, P. R.; Marshall, P. A.; Dawson, K.; Brunell, I. F.; Sutcliffe, C. J.; Potter, R. J. Vacuum Ultraviolet Photochemical Selective Area Atomic Layer Deposition of $\mathrm{Al}_{2} \mathrm{O}_{3}$ Dielectrics. AIP Adv. 2015, 5, 017115.

(51) Kim, W.-H.; Minaye Hashemi, F. S.; Mackus, A. J. M.; Singh, J.; Kim, Y.; Bobb-Semple, D.; Fan, Y.; Kaufman-Osborn, T.; Godet, L.; Bent, S. F. A Process for Topographically Selective Deposition on 3D Nanostructures by Ion Implantation. ACS Nano 2016, 10, 4451-4458.

(52) Sinha, A.; Hess, D. W.; Henderson, C. L. Area Selective Atomic Layer Deposition of Titanium Dioxide: Effect of Precursor Chemistry. J. Vac. Sci. Technol. B 2006, 24, 2523-2532.

(53) Coll, M.; Palau, A.; Gonzalez-Rosillo, J. C.; Gazquez, J.; Obradors, X.; Puig, T. Integration of Atomic Layer Deposition $\mathrm{CeO}_{2}$ Thin Films with Functional Complex Oxides and 3D Patterns. Thin Solid Films 2014, 553, 7-12.

(54) Ellinger, C. R.; Nelson, S. F. Selective Area Spatial Atomic Layer Deposition of $\mathrm{ZnO}, \mathrm{Al}_{2} \mathrm{O}_{3}$, and Aluminum-Doped $\mathrm{ZnO}$ Using Poly(vinyl Pyrrolidone). Chem. Mater. 2014, 26, 1514-1522.

(55) Levy, D. H.; Ellinger, C. R.; Nelson, S. F. Metal-Oxide ThinFilm Transistors Patterned by Printing. Appl. Phys. Lett. 2013, 103, 043505.

(56) Färm, E.; Kemell, M.; Santala, E.; Ritala, M.; Leskelä, M. Selective-Area Atomic Layer Deposition Using Poly(vinyl Pyrrolidone) as a Passivation Layer. J. Electrochem. Soc. 2010, 157, K10-K-14.

(57) Park, K. J.; Parsons, G. N. Selective Area Atomic Layer Deposition of Rhodium and Effective Work Function Characterization in Capacitor Structures. Appl. Phys. Lett. 2006, 89, 043111.

(58) Mullings, M. N.; Lee, H.-B.-R.; Marchack, N.; Jiang, X.; Chen, Z.; Gorlin, Y.; Lin, K.-P.; Bent, S. F. Area Selective Atomic Layer Deposition by Microcontact Printing with a Water-Soluble Polymer. J. Electrochem. Soc. 2010, 157, D600-D604.

(59) Biercuk, M. J.; Monsma, D. J.; Marcus, C. M.; Becker, J. S.; Gordon, R. G. Low-Temperature Atomic-Layer-Deposition Lift-off Method for Microelectronic and Nanoelectronic Applications. Appl. Phys. Lett. 2003, 83, 2405-2407.

(60) Sinha, A.; Hess, D. W.; Henderson, C. L. Area-Selective ALD of Titanium Dioxide Using Lithographically Defined Poly(methyl Methacrylate) Films. J. Electrochem. Soc. 2006, 153, G465-G469.

(61) Suresh, V.; Huang, M. S.; Srinivasan, M. P.; Guan, C.; Fan, H. J.; Krishnamoorthy, S. Robust, High-Density Zinc Oxide Nanoarrays by Nanoimprint Lithography-Assisted Area-Selective Atomic Layer Deposition. J. Phys. Chem. C 2012, 116, 23729-23734.

(62) Levy, D. H.; Nelson, S. F.; Freeman, D. Oxide Electronics by Spatial Atomic Layer Deposition. J. Disp. Technol. 2009, 5, 484-494.

(63) Coll, M.; Gazquez, J.; Palau, A.; Varela, M.; Obradors, X.; Puig, T. Low Temperature Epitaxial Oxide Ultrathin Films andNanostructures by Atomic Layer Deposition. Chem. Mater. 2012, 24, 37323737.

(64) Dandley, E. C.; Lemaire, P. C.; Zhu, Z.; Yoon, A.; Sheet, L.; Parsons, G. N. Wafer-Scale Selective-Area Deposition of Nanoscale Metal Oxide Features Using Vapor Saturation into Patterned Poly(methyl Methacrylate) Templates. Adv. Mater. Interfaces 2016, 3, 1500431 .

(65) Avila, J. R.; Emery, J. D.; Pellin, M. J.; Martinson, A. B. F.; Farha, O. K.; Hupp, J. T. Porphyrins as Templates for Site-Selective Atomic Layer Deposition: Vapor Metalation and in Situ Monitoring of Island Growth. ACS Appl. Mater. Interfaces 2016, 8, 19853-19859.

(66) Chopra, S. N.; Zhang, Z.; Kaihlanen, C.; Ekerdt, J. G. Selective Growth of Titanium Nitride on $\mathrm{HfO} 2$ on Surfaces with Topography. Chem. Mater. 2016, 28, 4928-4934.

(67) Yeo, L. P.; Yan, Y. H.; Lam, Y. C.; Chan-Park, M. B. Design of Experiment for Optimization of Plasma-Polymerized Octafluorocyclo- butane Coating on Very High Aspect Ratio Silicon Molds. Langmuir 2006, 22, 10196-10203.

(68) Li, X.; Hua, X.; Ling, L.; Oehrlein, G. S.; Barela, M.; Anderson, H. M. Fluorocarbon-Based Plasma Etching of SiO: Comparison of C4F6/Ar and C4F8/Ar Discharges. J. Vac. Sci. Technol., A 2002, 20, 2052-2061.

(69) Abd Aziz, S. N. Q. A.; Pung, S.-Y.; Ramli, N. N.; Lockman, Z. Growth of $\mathrm{ZnO}$ Nanorods on Stainless Steel Wire Using Chemical Vapour Deposition and Their Photocatalytic Activity. Sci. World J. 2014, 2014, 252851.

(70) Avila, J. R.; Demarco, E. J.; Emery, J. D.; Farha, O. K.; Pellin, M. J.; Hupp, J. T.; Martinson, A. B. F. Real-Time Observation of Atomic Layer Deposition Inhibition: Metal Oxide Growth on Self-Assembled Alkanethiols. ACS Appl. Mater. Interfaces 2014, 6, 11891-11898.

(71) Haider, A.; Yilmaz, M.; Deminskyi, P.; Eren, H.; Biyikli, N. Nanoscale Selective Area Atomic Layer Deposition of $\mathrm{TiO}_{2}$ Using EBeam Patterned Polymers. RSC Adv. 2016, 6, 106109-106119.

(72) Vallat, R.; Gassilloud, R.; Eychenne, B.; Vallée, C. Selective Deposition of $\mathrm{Ta}_{2} \mathrm{O}_{5}$ by Adding Plasma Etching Super-Cycles in Plasma Enhanced Atomic Layer Deposition Steps. J. Vac. Sci. Technol., A 2017, 35, 01B104. 